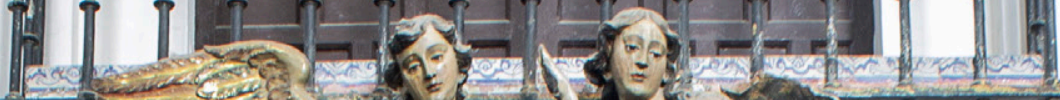

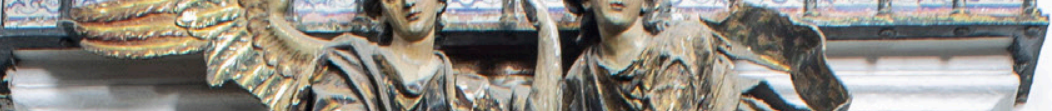

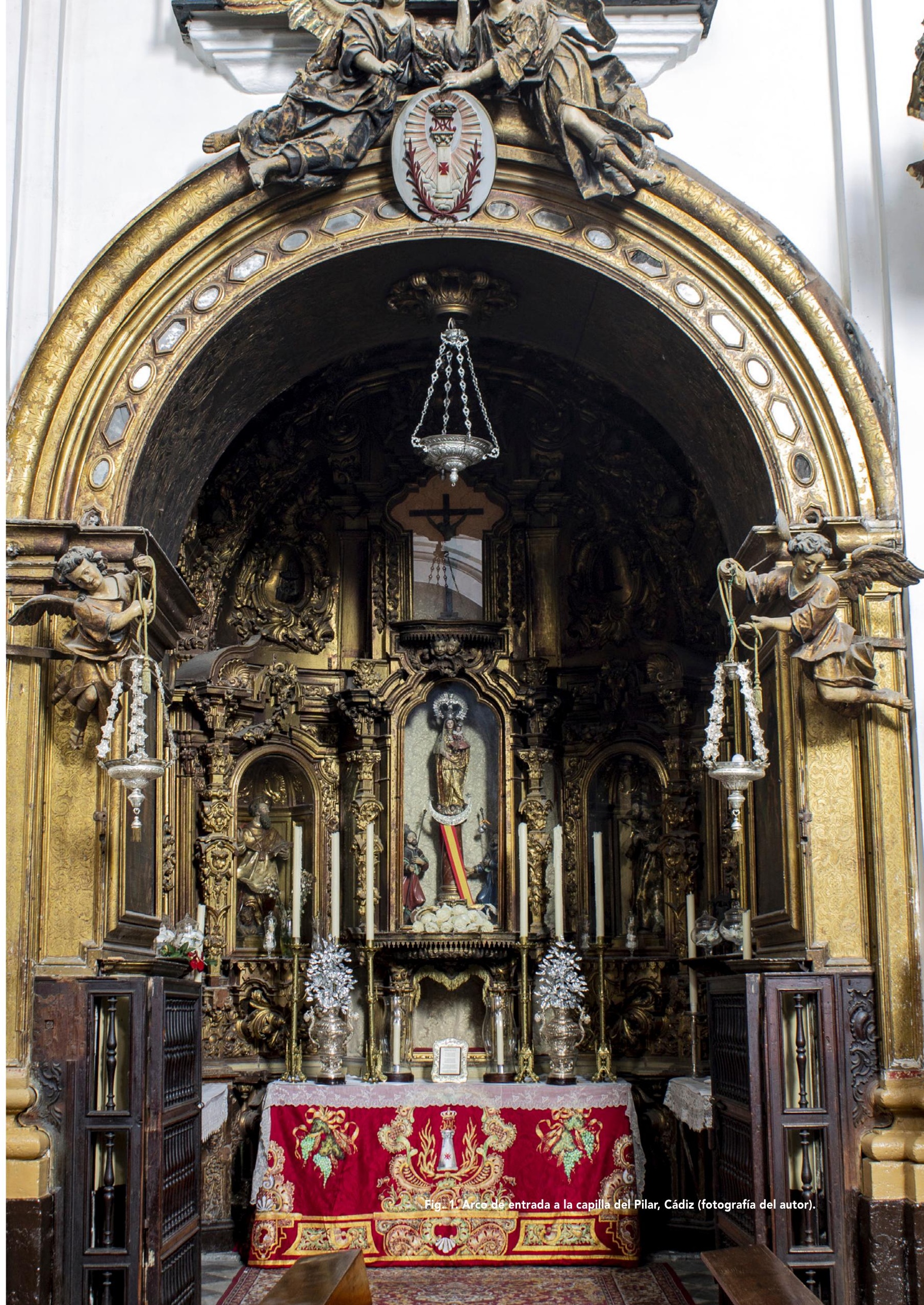




\title{
Francisco López y Gonzalo Pomar en la capilla de la Archicofradía del Pilar de Cádiz
}

Francisco López and Gonzalo Pomar in the chapel of the Pilar brotherhood in Cádiz

\author{
Carlos Maura Alarcón \\ Universidad de Sevilla, España \\ carlos13-5-1995@hotmail.com \\ https://orcid.org/0000-0001-6373-2821
}

\section{Resumen}

La capilla de la archicofradía de Nuestra Señora del Pilar es hoy uno de los conjuntos más inalterados del Cádiz del siglo XVIII. El conjunto de retablos de su interior y las interesantes imágenes que alberga son el objeto de este artículo, pues tras la exhumación del archivo histórico de la hermandad nos es posible arrojar nueva luz acerca de sus autores. Así, Francisco López y Gonzalo Pomar, notables artistas establecidos en la ciudad, tendrían un destacado protagonismo, como principales configuradores del espacio.

Palabras clave: capilla; Pilar; Cádiz; Francisco López; Gonzalo Pomar.

\begin{abstract}
The chapel of Nuestra Señora del Pilar is nowadays one of the most original groups from the XVIII century in Cádiz. Its altarpieces and the interesting images we found inside are the object of this article, because after the investigation in the brotherhood's historical archive we can shed some light about its authors. So, Francisco López and Gonzalo Pomar, high artists established in the city, will have an eminent protagonism, as main configurers of the whole espace.
\end{abstract}

Keywords: chapel; Pilar; Cádiz; Francisco López; Gonzalo Pomar. págs. 70-83.

Copyright (c) 2018 Carlos Maura Alarcón. Este es un artículo de acceso abierto distribuido bajo los términos de la licencia Creative Commons Attribution-NonCommercial-ShareAlike 4.0. International License (CC BY-NC-SA 4.0). 
El campo del retablo en Cádiz durante el siglo de las Luces es de un interés sobresaliente, debido a la cantidad y calidad de conjuntos que vieron la luz a lo largo de dicha centuria, una realidad ciertamente extraordinaria si tenemos en cuenta la producción del resto de focos cercanos. Tras un siglo XVII marcado por la dualidad entre Sevilla y Génova, no será hasta transcurridas largas décadas que podamos hablar de una escuela local de cierta entidad, la cual pervivirá hasta principios del siglo XIX, soportando incluso la llegada de las nuevas fórmulas academicistas. En sus comienzos, esta evolución del retablo en Cádiz está marcada por la ausencia de un sistema gremial vigoroso, como sí ocurría en Sevilla, lo que conllevó la participación de otros artistas en la configuración y supervisión de estas máquinas lignarias, tales como pintores, plateros o doradores, reflejo este, en definitiva, de la débil entidad que tenía la escuela local ${ }^{1}$. No obstante, con el trascurso de los años, irá adquiriendo mayor protagonismo, y los artistas adscritos a ella pasarán de un discreto segundo plano a dirigir proyectos de notable envergadura, tanto en Cádiz como en las ciudades del entorno.

Como suele ocurrir con la cronología de los retablos barrocos, diferenciamos las etapas en Cádiz por los soportes que utilizan. Desde mediados del siglo XVII, predomina el uso de la columna salomónica como elemento articulador del espacio, comenzando con un uso simbólico hasta desembocar en una función decorativa. Así lo evidencia la presencia de ella en el retablo mayor de la Catedral Vieja, obra de Alejandro de Saavedra en 1640, donde dos columnas torsas marcan la calle central en la que se encontraba un tabernáculo de ébano y plata -hoy perdido- guardando las Sagradas Especies, al modo en el que Jaquín y Boaz cobijaban el Arca de la Alianza en el Templo de Jerusalén ${ }^{2}$. En su vertiente decorativa, se puede apreciar su presencia en el retablo mayor de la iglesia conventual de Santo Domingo, de 1683, obra de mestizaje, pues su diseño se debe a Juan González de Herrera y su hechura a los talleres genoveses de Frugone y Ponsonelli, concertadas a través de Andrea Andreoli³.

Al entrar el siglo XVIII, esta situación se siguió manteniendo, pues los comitentes continuaron encargando sus retablos preferentemente a las escuelas sevillana y genovesa, quienes impusieron, además, las modas a los artistas de Cádiz. Fue entonces cuando la corriente salomónica comenzó a decaer en favor del estípite como elemento articulador del retablo, el cual se mantendrá con fuerza hasta la segunda mitad de siglo. A su llegada se sumaron otra serie de novedades tanto estructurales como ornamentales, cuya aplicación ya se había puesto en práctica a finales de la centuria anterior en Castilla de la mano de José Benito de Churriguera ${ }^{4}$, las cuales llegaron a Andalucía gracias a la figura estelar de Jerónimo de Balbás. Así, el movimiento envolvente de la planta, el cascarón limitado por un arco de medio punto que cierra la bóveda y la aplicación de una decoración tallada basada en elementos vegetales anticipan en Salamanca los recursos que se aplicarán incansablemente en los retablos dieciochescos en Cádiz.

1. Se profundiza en esta idea en ALONSO DE LA SIERRA FERNÁNDEZ, Lorenzo, "Diversidad profesional en la creación del retablo. El Cádiz barroco", Boletín de arte, n. ${ }^{\circ} 20,1999$, págs. 155-166.

2. Sobre el retablo de la actual parroquia de Santa Cruz, véase SANCHO DE SOPRANIS, Hipólito, "Alejandro de Saavedra, entallador", Archivo hispalense: revista histórica, literaria y artística, t. 4, n. ${ }^{\circ} 10,1945$, págs. 3-75.

3. La atribución de las trazas a Herrera se encuentra en DÍAZ, Vicente, "El retablo de Santo Domingo de Cádiz", Archivo dominicano, 1995, pág. 351.

4. Sobre la tipología de retablo churrigueresco, puede consultarse RODRíGUEZ GUTIÉRREZ DE CEBALLOS, Alfonso, Los Churriguera, Madrid, Instituto Diego Velázquez, 1971, págs. 16, 20-23, o, del mismo autor, "El retablo barroco en Salamanca: materiales, formas, tipologías", Imafronte, n. ${ }^{\circ}$ 5-8, 1995-1998, págs. 225-258. 
En cuanto a la recepción de estas formas, no debemos olvidar que Balbás estuvo afincado en la ciudad entre 1702 y 1703, antes de pasar a Sevilla, y aquí se le documentan labores de diseño de la torre del edificio consistorial, así como algunos pagos al frente de las obras, hasta que fuera sustituido por el alarife Blas Díaz 5 . Resulta extraño que la población gaditana no aprovechara la estancia del zamorano con un mayor número de encargos, pues es seguro que debió de acudir aquí con cierto prestigio, como se desprende de que trabajara para la corporación municipal recién llegado de Madrid; sin duda, la Guerra de Sucesión debió hacer languidecer a la población y a sus recursos, habida cuenta de la importancia que tuvo Cádiz en la contienda ${ }^{6}$. Aun así, la adquisición de un lenguaje fuertemente influido por la creación de Balbás manifiesta que su etapa en la ciudad no pasó desapercibida para los artistas, tal y como evidencian numerosos retablos, como el mayor de San Lorenzo, obra de notable magnitud debida a Francisco López y que supone uno de los hitos del retablo en la trimilenaria población ${ }^{7}$.

En torno a 1750 se implantarán nuevos criterios decorativos, que tendrán su denominador común en el uso de la rocalla, elemento proveniente de Francia y que definirá al retablo rococó ${ }^{8}$. En este proceso de cambio, la Catedral Nueva funciona como catalizador, al requerir un alto número de escultores, diseñadores y tallistas para su decoración. Todo parece indicar que la introducción de la rocalla en la ciudad se debió a uno de estos artistas llegados para trabajar en esta empresa, Cayetano de Acosta, portugués de nacimiento, y quien desde 1738 se encuentra citado en sus libros de cuentas ${ }^{9}$. Durante su estancia en la ciudad (c.1738-1750), realizó otras labores aparte de las decorativas, como escultóricas o de diseńo de retablos ${ }^{10}$. Desgraciadamente, no conservamos el retablo que le encargó en 1743 la archicofradía de la Virgen de los Ángeles, en la entonces ayuda de parroquia del Rosario, el cual estaba realizado en madera y fue reemplazado en 1783 por el actual, obra de Torcuato Benjumeda, el cual nos permitiría saber qué impacto tuvieron sus diseños en los artistas locales ${ }^{11}$. Sí sabemos que, junto a Acosta, en él trabajaron Benito de Hita y Castillo, quien realizó la imagen titular, y Gonzalo Pomar, a quien se le adscriben otras obras menores ${ }^{12}$. Del mismo año son otros retablos atribuidos a él, los adosados a los pilares de la iglesia de Santiago, en los que se emplean diferentes soluciones, tales como el estípite o pabellón, dependiendo del formato de la imagen que los presida y en los que se ha visto un notable influjo de la producción de Pedro Duque Cornejo ${ }^{13}$.

A partir de entonces, es perceptible la aparición de nuevos artistas formados en el ámbito local, y que protagonizarán importantes empresas artísticas en el entorno gaditano. Esta presencia en Cádiz de unas

\footnotetext{
5. ALONSO DE LA SIERRA FERNÁNDEZ, Lorenzo y TOVAR DE TERESA, Guillermo, "Diversas facetas de un artista de dos mundos: Gerónimo de Balbás en España y México", Atrio. Revista de Historia del Arte, n. ${ }^{\circ} 3,1991$, págs. 79-107.

6. Esta idea se defiende en el estudio de Lorenzo Alonso de la Sierra y Guillermo Tovar de Teresa. Ibídem, pág. 80.

7. Sobre este autor y el retablo de San Lorenzo, véase ALONSO DE LA SIERRA FERNÁNDEZ, Lorenzo y HERRERA GARCÍA, Francisco, "Francisco López y la difusión del barroco estípite en el retablo bajo-andaluz" , Archivo hispalense: revista histórica, literaria y artística, n. ${ }^{\circ} 230,1992$, págs. 121-155.

8. Un cumplido resumen de esta corriente en Cádiz en ALONSO DE LA SIERRA FERNÁNDEZ, Lorenzo, "El retablo rococó en Cádiz y su entorno", Archivo hispalense: revista histórica, literaria y artística, n. ${ }^{\circ} 248,1998$, págs. 95-110.

9. Ibídem, pág. 95.

10. PLEGUEZUELO HERNÁNDEZ, Alfonso, "Aportaciones a la biografía y obra de Cayetano de Acosta: la fase gaditana", Seminario de Estudios de Arte y Arqueología, n. ${ }^{\circ} 54,1988$, págs. 483-501.

11. ALONSO DE LA SIERRA FERNÁNDEZ, Lorenzo, "Novedades sobre la obra de Cayetano de Acosta en Cádiz", Atrio. Revista de Historia del Arte, n. ${ }^{\circ} 8-9,1996$, págs. 133-138.

12. La primera vez que se atribuye esta imagen a Hita y Castillo es en SANCHO DE SOPRANIS, Hipólito, "La imagen de la Reina de los Ángeles del Rosario", La información del lunes, 1958, pág. 19. En el mismo artículo se recoge el trabajo de Pomar.

13. ALONSO DE LA SIERRA FERNÁNDEZ, Lorenzo, "El retablo rococó...", op. cit., pág. 96. A su vez, la influencia de Duque Cornejo en Acosta se estudia ya en TAYLOR, René, El entallador e imaginero Pedro Duque Cornejo (1678-1757), Madrid, Instituto de España, 1983, págs. $96-99$.
} 
obras de rasgos comunes -rocallas, elementos calados, complejas escenografías- hizo ya desde mediados del siglo XX plantearse la existencia de una corriente de artistas activos entre la capital y Jerez de la Frontera ${ }^{14}$; a partir de entonces, hemos podido ir descubriendo más datos acerca de estos artistas, los cuales beben directamente de Acosta. No obstante, esto no significa que los artistas de la escuela sevillana y genovesa no siguieran levantando retablos, pues ciertamente continuaron recibiendo un alto número de encargos, como evidencian importantes obras. Por ejemplo, la capilla que levantó la archicofradía de la Divina Pastora para acoger a su titular se dotó de tres enormes máquinas lignarias encargadas a Julián Ximénez, quien contó con la colaboración de Benito de Hita y Castillo, artistas que dejaron en esta iglesia algunas de sus más destacadas creaciones ${ }^{15}$. De la vertiente italiana, destacaremos el retablo marmóreo que guarece a la Virgen de la Misericordia de Savona, obra de Alessandro Aprile para el convento de Santo Domingo en 1762, el cual tuvo tan buena acogida que, pocos años más tarde, los padres dominicos decidieron levantar en el testero opuesto un retablo exactamente similar, pero realizado en madera ${ }^{16}$. De entre todos los artistas de esta corriente local, citaremos aquí a Gonzalo Pomar, como exponente de esta tendencia y como protagonista en la capilla objeto de nuestro trabajo.

De él, poco se ha sabido hasta fechas muy recientes. Hipólito Sancho de Sopranis es el primero en publicar sus coordenadas vitales, fechando su nacimiento en Ubrique en 1711 y su muerte en Cádiz en 1795, tras haber documentado su participación en el triunfo erigido en honor de la Virgen del Rosario por su protección en el maremoto de $1755^{17}$. Desde entonces, el estudio de su obra ha venido engrandeciéndose con otros retablos atribuidos y documentados. En 1934, se publicaba el contrato de realización por el que Pomar se comprometía a entregar el retablo de la capilla de Jesús Nazareno de Cádiz y, más recientemente, María Pemán hacía lo propio con el mayor de la iglesia de San Francisco, aportando dos importantes piezas de las que partir para conocer su estilo ${ }^{18}$. El primero de ellos, comenzado en 1757 , muestra ya la utilización de un lenguaje muy característico, basado, a nivel arquitectónico, en la recuperación de la columna clásica de orden corintio, que en este retablo se ha colocado en los dos extremos, enmarcando el conjunto. No obstante, lo más característico de este artista es la abundancia de elementos decorativos, especialmente la rocalla y los angelotes, que pueblan todas las partes de esta gran máquina. Una evolución de su estilo se hace perceptible en el retablo de la iglesia franciscana, concertado en 1763, donde se ve de forma más nítida la aplicación de un esquema reticular, seguramente obligado aquí por la disposición del presbiterio, estrecho y alto. No se aprecia, aun así, como un rasgo arcaizante, puesto que, al elevar la calle central y la altura de los soportes y hacer girar estos respecto a sus bases, consigue insertar un notable sentido ascendente a la composición. En este caso, el suave efecto claroscurista, derivado de la concentración de su ornamentación, ha llevado al profesor Alonso de la Sierra a relacionar esta obra con el influjo de los Churriguera, pese a que la decoración se base aquí prácticamente en las rocallas ${ }^{19}$. Una obra de reciente atribución, el retablo mayor de la iglesia de la

14. BAIRD, Joseph, "The retables of Cádiz and Jerez in the 17th and 18th centuries", Anales del Instituto de Investigaciones Estéticas, n. ${ }^{\circ} 26,1957$, págs. 39-49.

15. Sobre esta capilla y sus retablos, véase SANCHO DE SOPRANIS, Hipólito, "El escultor sevillano Julián Ximénez", Archivo hispalense: revista de historia, literatura y arte, $\mathrm{n} .^{\circ} 43-44,1950$, págs. 247-253.

16. ALONSO DE LA SIERRA FERNÁNDEZ, Lorenzo, "Mármoles genoveses en Cádiz. Un retablo de Alessandro Aprile", Atrio. Revista de Historia del Arte, n. ${ }^{\circ} 7,1995$, págs. 57-66.

17. SANCHO DE SOPRANIS, Hipólito, "El maremoto de 1755 en Cádiz", Archivo hispalense: revista de historia, literatura y arte, t. 23, n. 74,1955, págs. 161-203.

18. MARTÍN CORDERO, Eduardo y SANCHO DE SOPRANIS, Hipólito, Documentos para la historia artística de Cádiz y su región, Jerez de la Frontera, Sociedad de estudios históricos jerezanos, 1939, pág. 28; PEMÁN MEDINA, María, "El maestro gaditano ensamblador y tallista Gonzalo Pomar", Gades, n. ${ }^{\circ} 3,1994$, págs. 35-47.

19. ALONSO DE LA SIERRA FERNÁNDEZ, Lorenzo, "El retablo rococó...", op. cit., pág. 99. 


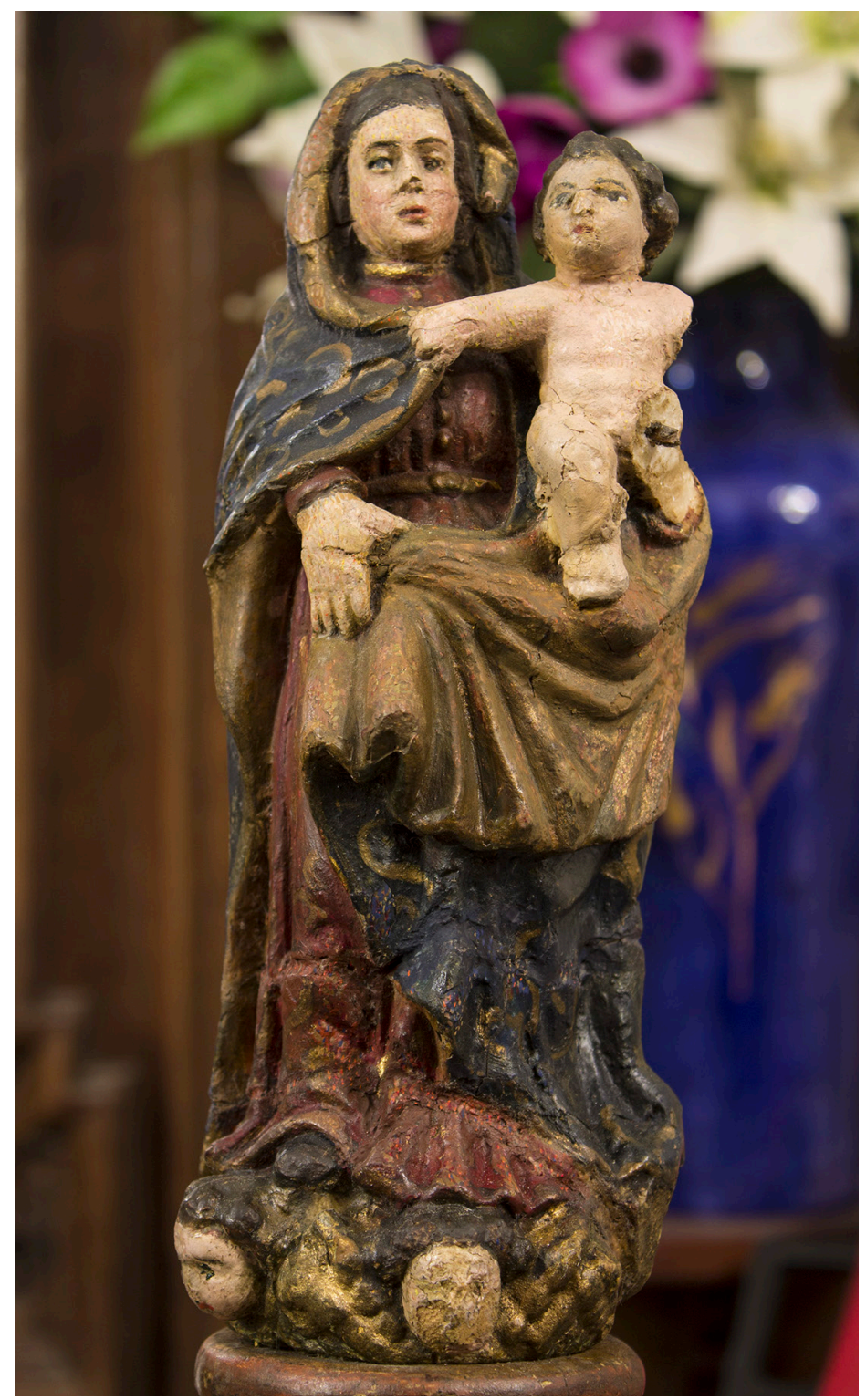

Fig. 2. Anónimo: Virgen del Pilar de Lorenzo Armengual, principios s. XVIII (fotografía del autor).
O de Sanlúcar de Barrameda, de $1767^{20}$, muestra una vuelta de tuerca más, y la decoración es prácticamentela protagonista del conjunto, que, arquitectónicamente, sigue mostrando el mismo lenguaje que en el resto de obras descritas. Sólo al final de su trayectoria, veremos una tímida inclusión de elementos clasicistas, como en el órgano de la iglesia de San Lorenzo, donde desaparece esta sobreabundancia de decoración en aras de favorecer la claridad de líneas ${ }^{21}$.

La capilla del Pilar, que ha pasado inadvertida por la historiografía artística, supone un notable hito en la historia del retablo en nuestra ciudad y nos permite ver cómo fueron sucediéndose los estilos conforme avanzaban los años. Para ello, será necesario ver cómo se conforma y evoluciona la hermandad de Nuestra Señora del Pilar, pues su historia explica las diferentes etapas por las que pasó este espacio. La cofradía se funda en $1730^{22}$, en torno a una devoción que fue introducida por el obispo Armengual a su llegada a la cátedra gaditana, pues sabemos que donó una imagen de la Virgen con esta advocación para presidir el retablo mayor de la iglesia de San Lorenzo (Fig. 2); cabe recordar de que el prelado fue ordenado sacerdote en Zaragoza, de cuya sede fue obispo auxiliar junto a Antonio Ibáñez de la Riba, por lo que se encargaría personalmente de propagar su devoción ${ }^{23}$. Así, en el mismo año en que fallece Armengual, nace esta corporación bajo el impulso de dos hermanos, Manuel y Jerónimo Ignacio Delfín, oriundos de Génova y

20. Ibídem, pág. 100.

21. Ibídem, pág. 101

22. En los libros de cuentas y de asiento, fechan a los primeros hermanos el 1 de enero de 1731, pero por otros testimonios sabemos que ya existía un grupo que le daba culto a la Virgen en 1730, auspiciado por el propio Armengual antes de su fallecimiento. Entre otros, un cuadro conservado en la casa de hermandad, que debe ser de estos primeros años, cita el 22 de julio de 1730 como el origen de este grupo. Véase AHAPC (Archivo Histórico de la Archicofradía del Pilar de Cádiz): libro 5, ff. 4r y ss.

23. Sobre la vida de Armengual, de reciente publicación es LARA VILLODRES, Antonio, El marquesado de Campo-Alegre, Málaga, Servicio de Publicaciones Unicaja, 2007. 
asentados en Cádiz como consecuencia de la actividad comercial que desempeñaban $\operatorname{ambos}^{24}$. Estos hermanos le dan a esta corporación la forma de una Compañía espiritual del Santo Rosario, un tipo de hermandad muy característica de la piedad gaditana de esta centuria que tiene su origen en el capuchino fray Pablo de Cádiz: desde finales del siglo XVII, influido seguramente por el rezo del Stellarium franciscano ${ }^{25}$, este fraile decide fundar por toda la ciudad quince hermandades, una por cada misterio del Rosario, para que salieran diariamente al anochecer a rezarlo por las calles aledañas a su sede. En nuestro caso, la conformación de la cofradía tiene lugar varias décadas después de la creación de las compañías de fray Pablo, pero participa de su misma estructura, algo que harían otras agrupaciones contemporáneas, como la de la Divina Pastora. Con el paso del tiempo, en torno a 1748 , los Delfín desaparecen de la vida de hermandad y el cargo de mayordomo pasa a ser ocupado por Juan Gutiérrez de Celis, personaje de capital importancia en la cofradía.

En estas décadas, sabemos por la documentación que la hermandad mudó su espacio dentro del templo de San

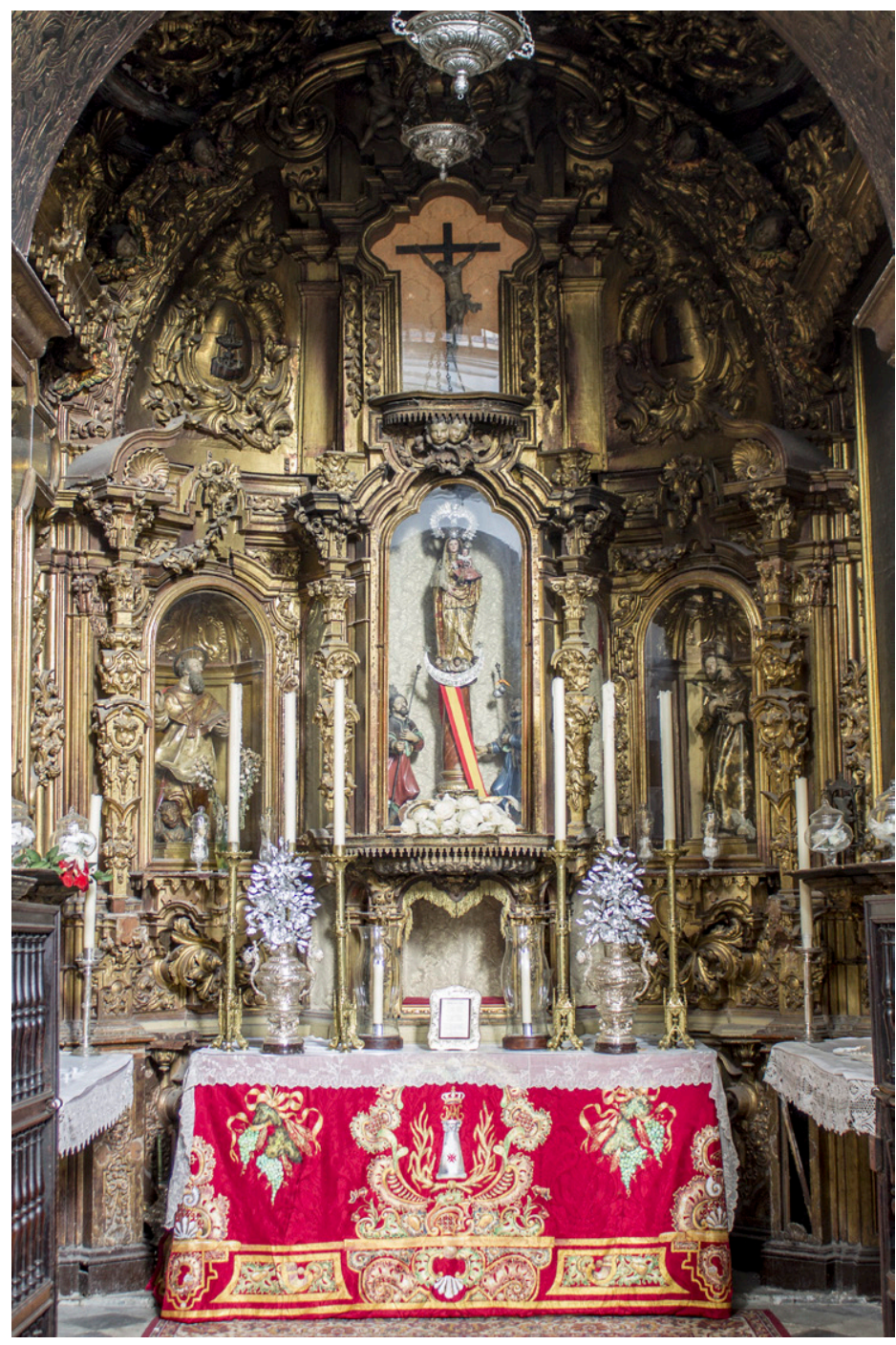

Fig. 3. Francisco López y Gonzalo Pomar (atrib.): Retablo principal de la capilla del Pilar, c. 1730/ c. 1748 (fotografía del autor).

Lorenzo, pues en origen radicaba en la capilla anexa a la actual, intercambiándose con la puerta lateral de la iglesia hacia $1747^{26}$. Igualmente, entre 1748 y 1753 sabemos que la capilla se encuentra en obras, ya que consta que las imágenes se trasladaron a casa de Jerónimo Ignacio Delfín, donde recibieron culto hasta que volvieron a ser entronizadas el 12 de octubre de $1753^{27}$. De su primera localización, pensamos que lo único que se conservó fue el retablo principal -que sólo fue actualizado estéticamente- y las imágenes que en él se incluyen, realizándose ex novo tanto los dos retablos laterales, dedicados a guarecer un lienzo representando

24. El testamento de Manuel Delfín se encuentra en AHPC (Archivo Histórico Provincial de Cádiz): sección Protocolos, libro CA 1271, ff. 275r-276v. 25. SANCHO DE SOPRANIS, Hipólito, "La devoción concepcionista en San Francisco de Cádiz", Archivo ibero-americano, n. ${ }^{\circ} 14,1954$, págs. 203-266.

26. ALONSO DE LA SIERRA FERNÁNDEZ, Lorenzo y ALONSO DE LA SIERRA FERNÁNDEZ, Juan Alonso, "Juan López de Algarín, Maestro de la Iglesia del Señor S. Lorenzo de Cádiz", Gades, n. ${ }^{\circ} 13,1985$, pág. 270; APSLC: libro de fábrica 1722-1748, documentos sin paginar.

27. AHAPC: libro 2, f. 85v. 
al Santo Cristo de Ribota y a una cruz de ébano y plata, presumiblemente, la primitiva cruz de guía ${ }^{28}$, así como la bóveda que remata el conjunto. Veamos a continuación estas piezas por separado.

Es el retablo principal una máquina lignaria resuelta en banco, cuerpo y ático y, horizontalmente, dividido en tres calles, la central más adelantada respecto a las laterales, que se encuentran levemente curvadas hacia el interior, dando la apariencia de ser un fondo de planta semicircular del que emerge el camarín central, que se resuelve a modo de vitrina (Fig. 3). El banco se eleva sobre un zócalo, sobresaliendo por encima de él la mesa de altar, que en este caso tiene la particularidad de presentar un cajón para guardar en su interior los libros y otros enseres de la hermandad. A su vez, el cuerpo principal se estructura mediante cuatro estípites que limitan las calles, diferenciándose en algunos módulos las dos columnas centrales de las de los dos extremos. Por último, el ático presenta un nicho cruciforme en la calle central y dos tarjas arriñonadas en las laterales, decoradas con relieves de rocalla, terminándose con un arco de medio punto decorado con cabezas de querubines. En la hechura del mismo, nos parece advertir, como anticipábamos, dos momentos diferenciados: uno primero en el que se realizó por entero, y un segundo en el que se introdujeron ciertos elementos decorativos, como las rocallas que decoran el camarín de las hornacinas laterales o las del ático, así como las veneras que se han colocado sobre los estípites, en el arranque del frontón. Estas piezas muestran una carnosidad mayor que las del resto del retablo, que están resueltas de manera más plana, evidenciando así una factura más temprana. Es por ello que pensamos que este retablo pudiera ser el que se encontraba en la primera capilla de esta corporación, siendo creado hacia los primeros años de la década de 1730, y que fue reformado entre 1748 y 1753, fecha en la que se trasladaría a la actual. Por los recursos y la técnica empleada, pensamos que la hechura original podría atribuirse a Francisco López, quien fue el autor del conjunto de los retablos principales de San Lorenzo, esto es, el mayor y los de los testeros del crucero ${ }^{29}$; además, esta hipótesis vendría refrendada por el hecho de que este mismo artista fue quien realizó el retablo del oratorio privado de Jerónimo Ignacio Delfín, mayordomo de la archicofradía durante sus dos primeras décadas ${ }^{30}$. La mano de López se revela en algunos detalles, como en el arco de querubines que coronan la parte superior, los cuales se encuentran ya presentes en los de San Lorenzo, donde se repite incluso la misma línea quebrada que los enmarca, así como en el tipo de decoración vegetal que se coloca en el banco, la cual se inserta en diversas partes del mismo retablo mayor parroquial. De la misma manera, el hecho de colocar los estípites centrales del retablo en esviaje respecto a la línea frontal de visión es un hecho muy particular que vuelve a repetir López -quizá siguiendo los diseños de Jerónimo de Balbás-, en el templete eucarístico del principal de este templo ${ }^{31}$.

Sin embargo, no es propio de su producción la decoración de rocallas, que se introdujeron en Cádiz, como vimos, a mediados de siglo, por lo que hemos de pensar que corresponden a una obra de actualización que sufrió el retablo durante las obras de 1748; así, pensamos tras la exhumación del archivo de la hermandad que podrían deberse a Gonzalo Pomar, quien fue hermano de ella desde su fundación hasta el fin de sus días y quien, además, se enterró en la bóveda de la capilla ${ }^{32}$. De la misma manera, consideramos que también

\footnotetext{
28. Ya se defiende esta hipótesis en ALONSO DE LA SIERRA FERNÁNDEZ, Lorenzo, Pietas Populi. Pervivencias [cat. exp.], Cádiz, Consejo de Hermandades y Cofradías, 2012, pág. 168

29. Sobre los trabajos de López en San Lorenzo, véase ALONSO DE LA SIERRA FERNÁNDEZ, Lorenzo y HERRERA GARCÍA, Francisco, "Francisco López y...", op. cit., págs. 136-143.

30. ALONSO DE LA SIERRA FERNÁNDEZ, Lorenzo, El retablo y sus autores en el Cádiz de la Edad Moderna [tesis doctoral inédita], Madrid, 1999, pág. 527. 31. ALONSO DE LA SIERRA, Lorenzo y HERRERA GARCÍA, Francisco, "Francisco López y...", op. cit., págs. $137-138$.

32. Su asiento de hermano en AHAPC: libro 1, f.73r. Sabemos que se enterró en la capilla por su testamento, hallado en AHPC: sección Protocolos, CA 1298, ff. 198r-201v.
} 
se deben adscribir a su catálogo el resto de retablos y la bóveda de madera tallada, que verían la luz durante el mismo período. En cuanto a Pomar, tiene documentados en la archicofradía importantes trabajos, como la renovación (el término es literal, tal y como viene en los libros de cuentas) en 1755 de la imagen titular por 375 reales de vellón, sin que sepamos si realizó una talla de nueva factura o si fue una modificación, aunque debió entregarla en madera vista, pues también se le pagaron a Esteban Pomé la cantidad de 2.220 reales de la misma moneda por aplicarle el estofado y la encarnadura ${ }^{33}$. Bajo nuestro punto de vista, y aunque no quede esclarecido en la documentación consultada, podría pensarse por su bajo coste que su talla correspondiera con un medallón de relieve, el cual presidiría el estandarte que utilizaban para rezar el rosario por las calles, y no a la titular de la capilla. A su vez, en 1756 , se le pagan 180 reales por el "costo y travajo de los dos golpes de talla que están por encima del arco de nuestra capilla"34.

A este mismo artista le atribuimos también la hechura de los dos retablos laterales, los cuales serían realizados ex novo en este período de renovación que

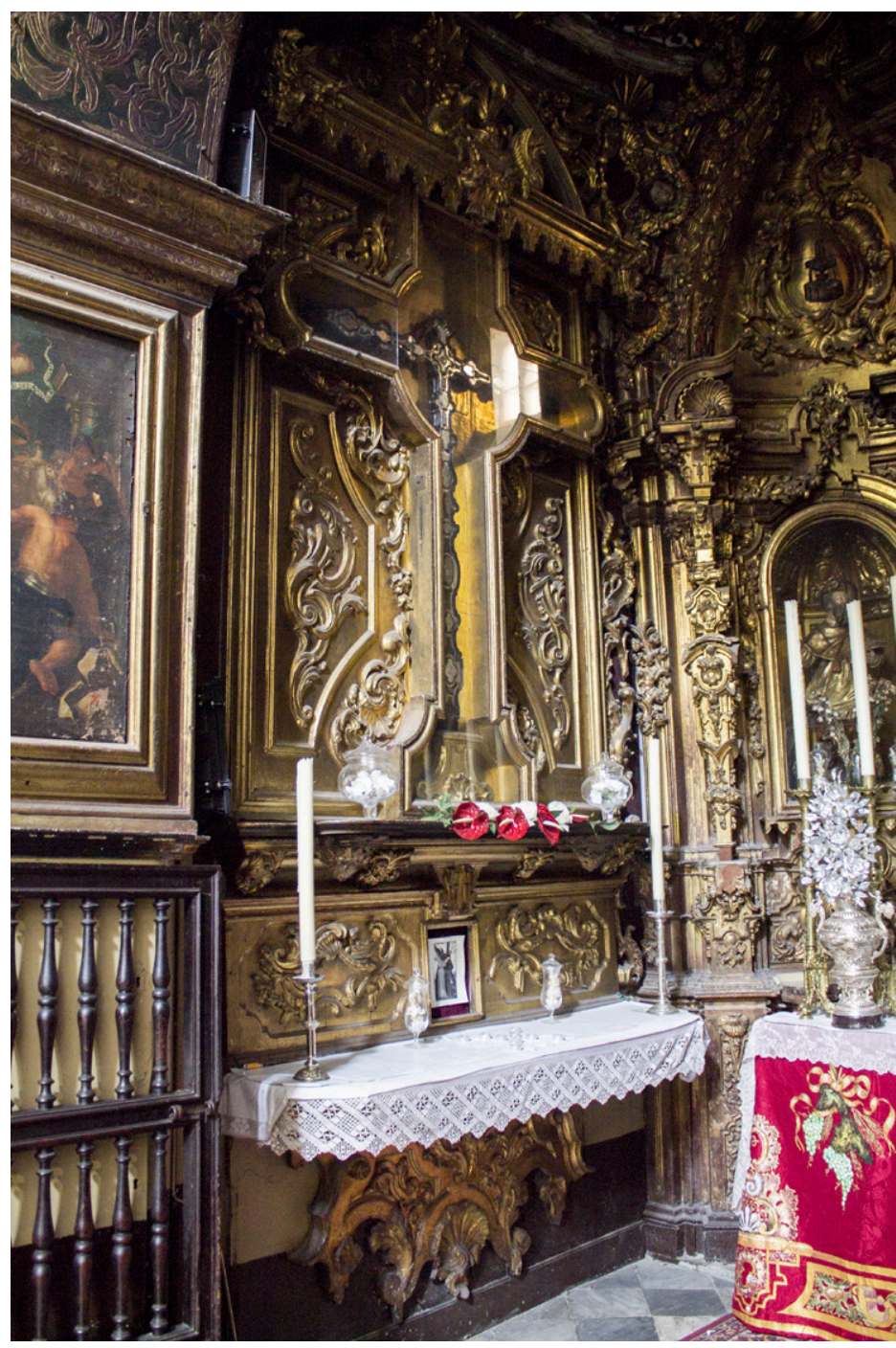

Fig. 4. Gonzalo Pomar (atrib.): Retablo del Evangelio de la capilla del Pilar, c. 1748 (fotografía del autor). sufre la corporación, habida cuenta de varias partidas para compra de madera para ejecutar dos mesas de altar para la capilla ${ }^{35}$, lo que vendría a corroborar que el principal ya se encontraba realizado y sólo era necesario hacer las de los dos retablos laterales. Esta devoción al Cristo de Ribota, muy inusual en este entorno, fue introducida en la capilla por el mayordomo segundo Miguel Vicente Ibáńez, junto a la pintura de pequeño formato situada en su mesa de altar con el tema de los corporales de Daroca. no hay duda de que el origen aragonés del personaje terminó de relacionar la capilla con aquel reino y sus devociones. De él sabemos que figura como hermano de la cofradía desde 1746 hasta 1755, ejerciendo además como mayordomo segundo durante los años de renovación

33. AHAPC: libro 5, ff. 118r y ss.

34. AHAPC: libro 5, f. $118 \mathrm{v}$.

35. AHAPC: libro 5, f. 73r. 


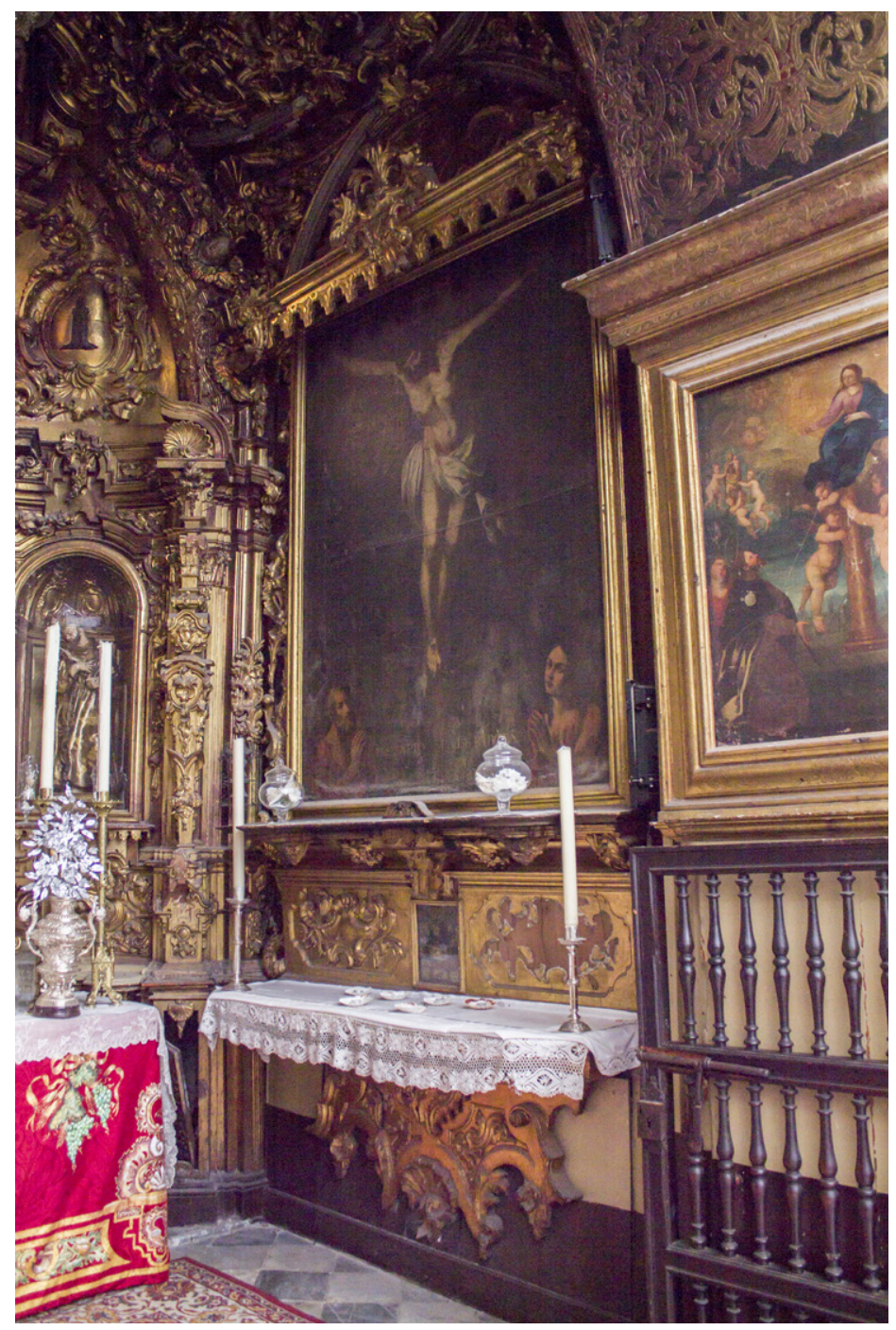

Fig. 5. Gonzalo Pomar (atrib.): Retablo de la Epístola de la capilla del Pilar, c. 1748 (fotografía del autor). de la capilla ${ }^{36}$. Además, que fue él quien introdujo en la capilla esta devoción nos lo reafirma un libro de 1845 publicado en Calatayud, en el que se afirma que en Cádiz es donde mayor devoción recibe el Cristo de Ribota, pues sanó a Miguel Vicente Ibáńez de la enfermedad que padecía, para cuyo recuerdo se abrió una estampa en 1747 y se decidió levantarle un retablo en esta capilla ${ }^{37}$. Este retablo del Santo Cristo de Ribota (Fig. 5) toma forma de gran marco con una mesa de altar sobre ménsula y guardamalleta de talla ornamental muy profusa. La imagen que preside este retablo es un lienzo anónimo fechable en la primera mitad del siglo XVIII, en el que se halla representado Cristo crucificado y, bajo él, dos ánimas en actitud orante; en la parte inferior, se encuentra la inscripción " $E l$ Santo Christo de Ribota", la cual permite su identificación. Especial interés por su originalidad posee la ménsula sobre la que simbólicamente se sostiene el retablo, resuelta de forma muy ornamental con un perfil sinuoso, el cual se ve finalizado en su parte inferior con una venera similar a las que se ven en el ático del altar principal de la capilla.

En el muro frontero a este retablo, se localiza el tercero de la capilla, presidido por una vitrina cruciforme que encierra la que sería la primitiva cruz de guía de la compañía espiritual (Fig. 4). La composición de este retablo es semejante a la que acabamos de describir, con la única salvedad de que, en el espacio que queda entre la vitrina y los límites del mismo, se han introducido paneles con elementos de talla muy carnosos basados en roleos vegetales. Sobre la mesa de altar, vemos un pequeño marco hoy presidido por un grabado contemporáneo de San Andrés, que a buen seguro no entraba parte del programa iconográfico original. En su lugar, pensamos que se encontraría una copia de la Virgen del Llanto, titular de la cofradía romana a la que se agregaron los hermanos del Pilar en

36. DEL COS, Mariano y DE EYARALAR, Felipe, Glorias de Calatayud y su antiguo partido, Calatayud, Imprenta de Celestina Coma, 1845, págs. 124-125.

37. AHAPC: libro 4, f. 23. Sabemos además por los libros de cuentas (AHAPC: libro 5, f. 115v) que murió en 1755 en las Puertas de Tierra, como consecuencia del maremoto del 1 de noviembre, siendo de los pocos gaditanos que perecieron mientras intentaban huir hacia San Fernando. Ya esta idea la defiende José María Collantes, por el origen aragonés del mayordomo, en una de las entradas del blog de la hermandad. 
1737 y con la que consiguieron el rango de archicofradía. Así, en una partida de cuentas de 1753, se detalla un pago de 375 reales de vellón "que ha costado una lámina del señor Santiago plateada que está puesta en la capilla, en el nicho donde se ha de colocar la Virgen del Llanto" ${ }^{38}$, sabiendo que esta ya se halla en su lugar en $1755^{39}$. No sabemos en qué fecha se retiró de este lugar ni bajo qué circunstancias, pero lo cierto es que es en este espacio en el que vemos más posible que se situase este simulacro, puesto que en el que se halla en el mismo lugar del retablo frontero es lógico que se disponga, como así se halla, la pintura del milagro de los corporales de Daroca, mientras que sobre la mesa de altar del retablo principal se encuentra el espacio para colocar la custodia durante la celebración de las exposiciones.

Igualmente, no queremos dejar de llamar la atención sobre la bóveda de la capilla (Fig. 6), en la que se inserta una decoración de talla muy menuda. Este elemento se divide en cuatro cuartos, correspondiendo uno de ellos con el ático del retablo principal, y presididos los restantes por una cartela con símbolos marianos: un pilar, una palma y un espejo con el anagrama de María en el centro. Alrededor de estos grupos, se dispone una decoración basada en hojarasca y rocalla, cuya resolución revela corresponder a la misma mano que ha realizado los dos retablos laterales y ha actualizado el principal. No ocurre así con el arco de entrada a la capilla, el cual se fecha entre 1757 y 1760, último ańo en el que destinan gastos para finalizar sus labores de dorado, y en el que vemos una decoración en estofado muy plana, que se debió al artista local José Rosillo, quien también sabemos que doró y policromó las portadas del presbiterio y del cancel de la iglesia de San Lorenzo $^{40}$. Esta bóveda de madera tallada supone de por sí un interés elevado, pues, pese a su delicado estado de conservación, es una de las dos únicas conservadas en la ciudad, de entre el alto número de capillas que tenían esta cubrición y que se fueron eliminando posteriormente, ya fuera por motivos estéticos o problemas estructurales.

Aunque fuera de los límites de este artículo, creemos que es necesario realizar algunos apuntes acerca de las imágenes que nos encontramos en la capilla, pues si bien se han atribuido certeramente las tallas de San Jerónimo y San Francisco a Maragliano, restan otras de semejante interés. Así, los ángeles de pequeño formato que flanquean el arco de ingreso son obra cercana a la producción del genovés Galleano, mientras que los que se encuentran sobre él evidencian pertenecer igualmente a la escuela genovesa, aunque no tan claro a este autor. La documentación no expresa información al respecto, más allá de que fueron donación de Juan Gutiérrez de Celis, pero sí indica que la policromía y estofado de estos últimos se debe a Francesco María Mortola, notable artista genovés afincado en Cádiz que también era miembro de la corporación, a quien se le conocen otros significativos trabajos en la ciudad. Además, ambos artistas dejaron varios trabajos en la iglesia, tales como la policromía de los ángeles lampadarios del presbiterio -en el caso de Mortola- o la hechura de la Virgen de los Dolores de la Orden Servita, atribuida con fundamento a Galleano ${ }^{41}$. En el interior, cabe destacar la imagen titular, obra de filiación genovesa cercana a 1730 y que bebe del icono original zaragozano, que quizás pudiera haber tenido alguna intervención a mediados del siglo XX, a tenor de

38. AHAPC: libro 5, f. 91 r.

39. AHAPC: libro 5, f. $105 \mathrm{v}$.

40. AHAPC: libro 5, f. 122r; APSLC: recibos justificativos de las cuentas (1763-1776), s/f. Agradecemos este último documento al citado profesor Lorenzo Alonso de la Sierra.

41. SÁNCHEZ PEÑA, José Miguel, Escultura genovesa. Artífices del Setecientos en Cádiz, Cádiz, 2006, pág. 78. 


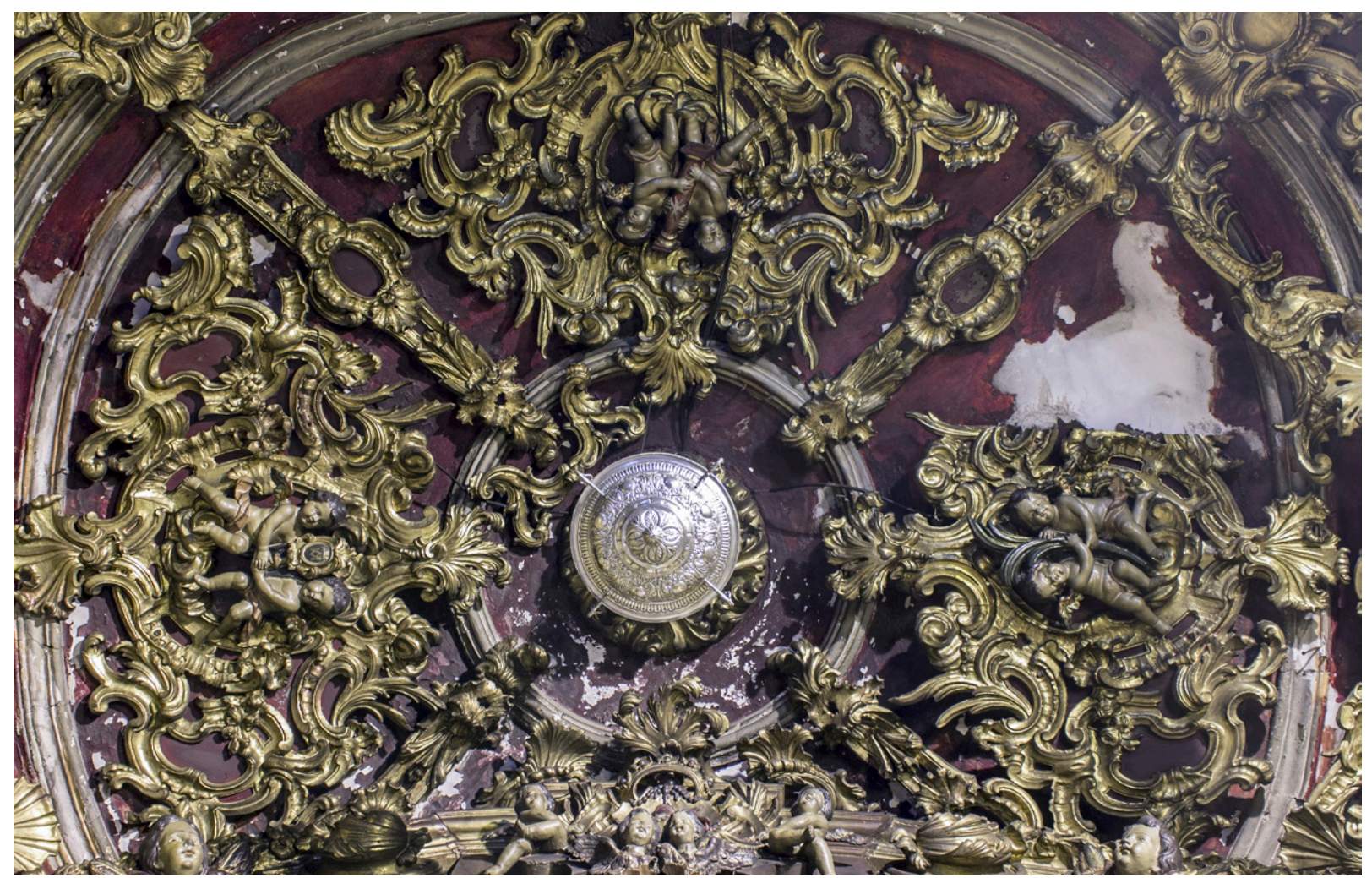

Fig. 6. Gonzalo Pomar (atrib.): Bóveda de la capilla del Pilar, c. 1748 (fotografía del autor).

pequeñas diferencias que nos parece advertir si comparamos su fisonomía actual con antiguas fotografías. Por último, el crucificado ubicado en el ático del retablo muestra una relación con los modelos de Maragliano, pudiéndose pensar en una obra cercana a él o a su taller.

Concluyendo, y a modo de recapitulación, podemos decir que, tras la exhumación del archivo histórico de la archicofradía del Pilar, hemos podido arrojar nueva luz acerca del retablo y sus creadores en el Cádiz dieciochesco. En primer lugar, se ha logrado establecer una cronología para los primeros pasos de esta corporación, que agrupó a notables prohombres de su momento, en cuya biografía tendrán cabida especial las aportaciones materiales y simbólicas a la hermandad. Así, nombres como los hermanos Delfín o Gutiérrez de Celis ya han sido subrayados en los estudios históricos acerca del comercio marítimo, por lo que estos aportes sumarían un aspecto de sus vidas hasta ahora no analizado, como es su gusto artístico. En segundo lugar, hemos podido atribuir, en base a la documentación y al análisis visual, los retablos y elementos mueble de esta capilla. Así, el autor del primer retablo que cobijó a la titular sería obra de Francisco López, importante artista que realizó, como vimos, el retablo mayor y los del crucero del mismo templo, así como otros en el ámbito provincial, como el de ánimas de la iglesia de San Lucas de Jerez de la Frontera. Posteriormente, con el cambio de ubicación dentro del templo gaditano, la hermandad renovó su estética adaptándola al gusto imperante protagonizado por la rocalla, encargándole a su hermano Gonzalo Pomar que actualizase el retablo principal y realizando el resto de retablos y la bóveda tallada, lo que constituye una de las primeras obras conocidas del artista ubriqueńo. 
Bibliografía

ALONSO DE LA SIERRA FERNÁNDEZ, Lorenzo y ALONSO DE LA SIERRA FERNÁNDEZ, Juan Alonso, "Juan López de Algarín, Maestro de la Iglesia del Señor S. Lorenzo de Cádiz", Gades, n. ${ }^{13}$, 1985, págs. 265-276.

ALONSO DE LA SIERRA FERNÁNDEZ, Lorenzo y TOVAR DE TERESA, Guillermo, “Diversas facetas de un artista de dos mundos: Gerónimo de Balbás en España y México", Atrio. Revista de Historia del Arte, n. ${ }^{\circ}$ 3, 1991, págs. 79-107.

ALONSO DE LA SIERRA FERNÁNDEZ, Lorenzo y HERRERA GARCÍA, Francisco, "Francisco López y la difusión del barroco estípite en el retablo bajo-andaluz", Archivo hispalense: revista histórica, literaria $y$ artística, n. ${ }^{\circ}$ 230, 1992, págs. 121-155.

ALONSO DE LA SIERRA FERNÁNDEZ, Lorenzo, "Mármoles genoveses en Cádiz. Un retablo de Alessandro Aprile", Atrio. Revista de Historia del Arte, n. ${ }^{\circ}$ 7, 1995, págs. 57-66.

ALONSO DE LA SIERRA FERNÁNDEZ, Lorenzo, "Novedades sobre la obra de Cayetano de Acosta en Cádiz”, Atrio. Revista de Historia del Arte, n. ${ }^{\circ} 8-9,1996$, págs. 133-138.

ALONSO DE LA SIERRA FERNÁNDEZ, Lorenzo, "El retablo rococó en Cádiz y su entorno", Archivo hispalense: revista histórica, literaria y artística, n. ${ }^{\circ}$ 248, 1998, págs. 95-110.

ALONSO DE LA SIERRA FERNÁNDEZ, Lorenzo, El retablo y sus autores en el Cádiz de la Edad Moderna [tesis doctoral inédita], Madrid, 1999.

ALONSO DE LA SIERRA FERNÁNDEZ, Lorenzo, "Diversidad profesional en la creación del retablo. El Cádiz barroco”, Boletín de arte s n. ${ }^{\circ}$ 20, 1999, págs. 155-166.

ALONSO DE LA SIERRA FERNÁNDEZ, Lorenzo, Pietas Populi. Pervivencias [cat. exp.], Cádiz, Consejo de Hermandades y Cofradías, 2012.

BAIRD, Joseph, "The retables of Cádiz and Jerez in the 17th and 18th centuries", Anales del Instituto de Investigaciones Estéticas, n. ${ }^{\circ}$ 26, 1957, págs. 39-49.

DEL COS, Mariano y DE EYARALAR, Felipe, Glorias de Calatayud y su antiguo partido, Calatayud, Imprenta de Celestina Coma, 1845.

DÍAZ, Vicente, "El retablo de Santo Domingo de Cádiz", Archivo dominicano, 1995.

LARA VILLODRES, Antonio, El marquesado de Campo-Alegre, Málaga, Servicio de Publicaciones Unicaja, 2007.

MARTÍN CORDERO, Enrique y SANCHO DE SOPRANIS, Hipólito, Documentos para la historia artística de Cádiz y su región, Jerez de la Frontera, Sociedad de estudios jerezanos, 1939.

PEMÁN MEDINA, María, "El maestro gaditano ensamblador y tallista Gonzalo Pomar", Gades, n.o 3, 1994 , págs. 35-47.

PLEGUEZUELO HERNÁNDEZ, Alfonso, "Aportaciones a la biografía y obra de Cayetano de Acosta: la fase gaditana”, Seminario de Estudios de Arte y Arqueología, n. ${ }^{\circ}$ 54, 1988, págs. 483-501.

RODRÍGUEZ GUTIÉRREZ DE CEBALlOS, Alfonso, Los Churriguera, Madrid, Instituto Diego Velázquez, 1971.

RODRÍGUEZ GUTIÉRREZ DE CEBALLOS, Alfonso, "El retablo barroco en Salamanca: materiales, formas, tipologías”, Imafronte, n.o 5-8, 1995-1998, págs. 225-258.

SÁNCHEZ PENAA, José Miguel, Escultura genovesa. Artifices del Setecientos en Cádiz, Cádiz, 2006.

SANCHO DE SOPRANIS, Hipólito, "Alejandro de Saavedra, entallador", Archivo hispalense: revista histórica, literaria y artística, t. 4, n. ${ }^{\circ} 10,1945$, págs. 3-75. 
SANCHO DE SOPRANIS, Hipólito, "El escultor sevillano Julián Ximénez", Archivo hispalense: revista de historia, literatura y arte, n. ${ }^{\circ}$ 43-44, 1950, págs. 247-253.

SANCHO DE SOPRANIS, Hipólito, "La devoción concepcionista en San Francisco de Cádiz", Archivo ibero-americano, n. ${ }^{\circ} 14,1954$, págs. 203-266.

SANCHO DE SOPRANIS, Hipólito, "El maremoto de 1755 en Cádiz", Archivo hispalense: revista de historia, literatura y arte, t. 23, n. ${ }^{74}$, 1955, págs. 161-203.

SANCHO DE SOPRANIS, Hipólito, "La imagen de la Reina de los Ángeles del Rosario", La información del lunes, 1958, pág. 19.

TAYLOR, René, El entallador e imaginero Pedro Duque Cornejo (1678-1757), Madrid, Instituto de España, 1983. 